\title{
Child Spinal Cord Compression without Trauma about 113 Cases in Senegal
}

\author{
Nourou Dine A. Bankole1,2, Moustapha Ndiaye ${ }^{2}$, Thioub Mbaye ${ }^{3}$, Youssoupha Sakho4, \\ Momar Code $\mathrm{Ba}^{3}$ \\ ${ }^{1}$ Departement de Neurochirurgie, Hopital des Spécialités, Rabat, Morrocco \\ ${ }^{2}$ Département de Neurologie, CHNU de Fann, Dakar, Senegal \\ ${ }^{3}$ Département de Neurochirurgie, CHNU de Fann, Dakar, Senegal \\ ${ }^{4}$ Departement de Neurochirurgie, HOGGY de, Dakar, Senegal \\ Email: bankolenouroudine@yahoo.fr,ngouille@hotmail.com, thioubmbaye@gmail.com,Yousakho@yahoo.fr, \\ bamcode@hotmail.com
}

How to cite this paper: Bankole, N.D.A., Ndiaye, M., Mbaye, T., Sakho, Y. and Ba, M.C. (2018) Child Spinal Cord Compression without Trauma about 113 Cases in Senegal. Yangtze Medicine, 2, 114-128. https://doi.org/10.4236/ym.2018.22013

Received: November 17, 2017

Accepted: June 8, 2018

Published: June 11, 2018

Copyright $\odot 2018$ by authors and Scientific Research Publishing Inc. This work is licensed under the Creative Commons Attribution International License (CC BY 4.0).

http://creativecommons.org/licenses/by/4.0/

(c) (i) Open Access

\begin{abstract}
Introduction: No-trauma spinal cord compressions are serious conditions not often described in children population. This study will discuss the epidemiological, clinical, biology and radiology assessment, the etiologies, the therapeutic and evolutionary aspects of this condition in children in Senegal. Patients and Methods: 113 children aged between 15 months and 18 years were managed in a 10 years period (from January 2005 to July 2015) for a non-traumatic spinal cord compression (average 8.3 years). Results: There was 66 males $(58 \%)$ and 47 females (42\%) with sex ratio of 1.40 . The main reasons for consultation were spinal deformity $(90 \%)$. The syndrome was complete in 52 patients (46\%) and incomplete in 61 patients (54\%). Plain radiography performed in 63 patients. The CT scan was performed in 21 patients and myelography performed in 4 patients. MRI was performed in 22 patients. There was intradural extramedullary process $(33.33 \%)$, the extradural lesions (14.28\%) and intramedullary process (28.57\%). Dorsal lesions were predominant (46\%) followed by the lumbar spine (27\%). The majority of the etiology was Pott's disease ( $80 \%)$ followed by tumors (17\%). Spondylitis to banal germs (2\%) and parasitic spinal cord compression (1\%) were rare. The histology of 6 patients was revealed 5\% neurofibroma Type II, 5\% extramedullary intradermal arachnoid cyst, 5\% intramedullary arachnoid cyst with cytochemistry of the CSF-like content, 5\% Anaplastic pilocytic astrocytoma, 5\% ganglioneuroma I terminal cone and 5\% meningothelial meningioma. Pott's disease has been cured by TB chemotherapy associated with a corset in $88.89 \%$ of cases. 2 patients of this group had benefited fixation after laminectomy. $68 \%$ of the patients had a favorable recovery, and $20 \%$ had com-
\end{abstract}


pletely recovered after an average of 7 months of treatment and three (3) patients had died. The compression by bilharzias is be cured by myelotomy and praziquantel with a favorable outcome. We have $94.74 \%$ decompressive laminectomy or laminotomy with tumor resection and four (4) Patients of this group benefited fixation; the patients who had intramedullary tumor benefited myelotomy and tumor resection; 3 patients in this group had benefited fixation after laminectomy 58\% of patients had good recovery and 1 pateint had died. Conclusion: In Africa, particularly in the tropics, Pott's disease remains the first etiology followed by vertebra-medullary tumors for no traumatic spinal cord compression of child.

\section{Keywords}

Spinalcord Compression, Child, Pott's Disease, Tumors, Spondylitis, Bilharzia

\section{Introduction}

Child's no-trauma spinal cord compression is neurological suffering related to compression of the marrow and its roots beyond any trauma. Diagnosis and/or therapeutic delay is risk of leaving definitive neurological sequelae. That is why it is a neurosurgical emergency and the interest of early diagnosis and management especially in the child with an unstable spine because it is growing.

In Africa, in the tropical zone, Pott's disease remains the first etiology of spinal cord compression in children followed by tumors [1].

Nowadays magnetic resonance imaging is the best exam who reveals the diagnosis of the medullary pathology with more precision.

Moreover, in the absence of the MRI we can be satisfied with the clinical data associated with the scan of the spine coupled to myelo-scan, the standard $\mathrm{x}$-ray incidence profile or in 3/4.

Anatomy cytopathology confirms the diagnosis and gives the histological type regardless of etiology.

Very few studies have been done in recent years concerning this children's pathology.

Our objective is to study epidemiological, clinical, paraclinical aspects, responsible etiologies and the therapeutic and evolutionary aspects of no-traumatic spinal cord compression in children.

\section{Materials and Methods}

It was an retrospective study about 113 children hospitalized in Senegal for no-traumatic spinal cord compression in the neurosurgery departments of Grand Yoff General Hospital and CHNU FANN Dakar, in the pediatric wards of the Aristide LeDantec Hospital and General Hospital of Grand Yoff and the Albert Royer Children's Hospital, the surgery department of the Regional Hospital 
Center of Thiès and the Neurology Department of the CHNU FANN Dakar from January 1, 2005 to July 312015.

The patients included were children whose age was less than or equal to 18 years and whose diagnosis had been accepted in the clinic (pain, stiffness, functional impotence) and neuroradiology (MRI, myeloscanner, standard radiographs). Patients not included were children hospitalized for traumatic spinal cord compression.

We studied and analyzed the following data:

- Identity, Gender, patient age

- Geographic origin

- History of the disease and Personal history

- Clinical data (signs of onset, neurological and extra neurological signs)

- Paraclinic data (Standard radiography of the spine, Myelography, CT, Magnetic resonance imaging, Biology, Anatomy cytopathology, other)

- The etiological data

- Treatments received and progress under treatment.

\section{Results}

\subsection{Socio-Epidemiological Data}

We have, 113 children aged 1 year 3 months to 18 years with an average age of 8 years are be hospitalized for non-traumatic spinal cord compression.

The majority of the children had less than 10 years $(60.18 \%)$ and came from the regions of Dakar (61.95\%), Diourbel (11.50\%) and Thiès (8.85\%). Mauritania and The Gambia were the regions of origin of patients who came from abroad (1.77\%). There was a predominance of 66 Males (58\%) for 47 Females (42\%) with a sex ratio of 1.40 .

\subsection{Clinical Data}

The main reasons for consultation were spinal deformity (90.26\%), spinal pain (71.68\%), and functional limb impairment (63.72\%).

The clinical symptomatology was polymorphous. Spinal cord compression syndrome was complete in 52 patients (46.02\%) and incomplete in 61 patients (53.98\%). The physical examination found a lesion syndrome (61.95\%) and/or a syndrome under lesion (89.39\%) and/or a spinal syndrome (90.26\%). The onset of symptomatology was insidious in $66.37 \%$ of cases and acute in $33.63 \%$ of cases.

Some patients had extra-neurological signs: 42 patients $(37.17 \%)$ had altered general state, 47 patients (41.59\%) had pleuropulmonary involvement, 14 patients $(12.39 \%)$ had adenoma, and 25 patients $(22.12 \%)$ had a clinical anemic syndrome.

\subsection{Paraclinic Data}

The standard radiography performed in 63 patients, showed vertebral (53.12\%), 
disco-vertebral (34.37\%), or disc (7.81\%) lesions associated with kyphosis (18.75\%) and/or scoliosis $19.17 \%)$.

Spine scanning performed in 21 patients revealed an expansive process compressing the marrow (18.28\%) and myeloscanning performed in four (4) patients revealed a stop of the contrast agent.

MRI performed in 22 patients showed extramedullary intradural processes (33.33\%), extradural lesions (14.28\%) and intramedullary processes (28.57\%). The myelography carried out in two (2) patients also showed a stop of the opaque column and of the contrast agent. Vertebral lesions were lytic-type geodesics, destruction of vertebral bodies, osteocondensation, aspects of vertebrae in patties; disc lesions were pinching or destroying. The dorsal stage was the majority (46\%) followed by lumbar (terminal cone) (27\%) and mixed or multi-stage (23\%), cervical lesions were rare (3.33\%).

In biology, 63 patients (59.43\%) had hypochromic microcytic anemia, 31 children (29.24\%) had high leukocytosis, 35 children (33.02\%) had thrombocytosis and one (1) had thrombocytopenia. The CRP and sedimentation rate were high in 73 children (64.60\%).

\subsection{Etiologic and Evolutionary Data}

Pott's disease was the majority ( $80 \%$ ) followed by tumors (17\%). Spondylodiscitis with mild bacteria (2\%) and parasitic spinal cord compression (1\%) were rare.

All children who suffered from Pott's disease be cured by TB chemotherapy associated with a corset in $88.89 \%$ of cases, 2 Patients of this group had benefited fixation after laminectomy. $68 \%$ of the patients had a favorable recovery, and $20 \%$ had completely recovered after an average of 7 months of treatment and 3 Patients had died. The child with medullary compression by bilharzia who first simulated an intramedullary tumor had benefited from laminectomy and treatment based on Praziquantel and had a favorable outcome. Patients with mild spondylitis had benefited from non-specific treatment and $2 / 3$ had complete recovery of their neurological disorders. We have $95 \%$ of children with tumors had benefited from decompressive laminectomy or laminotomy or myelotomy with tumor excision, 3 Patients in this group had benefited ostéosynthésis after laminectomy $58 \%$ of patients had good recovery and 1 patient had died.

\section{Discussion}

\subsection{Epidemiology}

In our series, the majority age groups were small children aged 3 to 10 years, with a total of 54 patients (48\%), followed by Grand children aged 10 years to 15 years with a total of 32 patients (28\%). Our results are substantially comparable with most studies [2] [3] [4] [5]. We have a predominance of Males (58\% of cases), which agrees with the data of the literature [3] [6] [7] [8]. 


\subsection{Clinical and Paraclinical Aspects}

\subsubsection{Clinical Aspects}

The spinal syndrome was made of, spinal pain (71.68\%), stiffness $(61.95 \%)$ and spinal deformity (90.26\%). Our results are comparable to other studies [3] [8] [9] (Table 1).

The lesional syndrome was radiculalgia with radicular deficit in 70 patients (61.95\%).

This lesional syndrome was found in $40 \%$ of cases in the Obilat study [8].

The syndrome under lesion was found in 101 patients (89.39\%); it was made of motor disorders (78.76\%), sensory disorders (17.70) and sphincter disorders (13.27\%). Our results are consistent with most literature data [9] [10] [11] (Tables 2-4).

Table 1. Spinal cord syndrome.

\begin{tabular}{cccc}
\hline Authors & Pain \% & Stiffness \% & Deformity \% \\
\hline Obilat [8] & 13 & 20 & 11.11 \\
Arthuis et Turpin [9] & 49.30 & 64 & 30 \\
Elboukili [3] & 67.67 & 27 & 27 \\
Our Study & 71.68 & 61.95 & 90.26 \\
\hline
\end{tabular}

Table 2. Motor disorders under lesion.

\begin{tabular}{cc}
\hline Authors & Percentages \% \\
\hline Obilat [8] & 91 \\
Arthuis et Turpin [9] & 82 \\
Lewis [11] & 67 \\
Elboukili [3] & 84 \\
Our Study & 78.76 \\
\hline
\end{tabular}

Table 3. Sensitive lesions under lesion.

\begin{tabular}{cc}
\hline Authors & Percentages \% \\
\hline Elboukili [3] & 33 \\
Bernardi [10] & 14.44 \\
Our Study & 17.70 \\
\hline
\end{tabular}

Table 4. Sphincter disorders under lesion.

\begin{tabular}{cc}
\hline AuThors & Percentages \% \\
\hline Obilat [8] & 51.10 \\
Arthuis et Turpin [9] & 30 \\
Bernardi [10] & 39.40 \\
Elboukili [3] & 28 \\
Our Study & 13.27
\end{tabular}




\subsubsection{Paraclinical Aspects}

MRI is the fundamental paraclinical exam in the medullary pathology [12] [13] [14].

That is not invasive and be tolerated well and have several advantages over other investigations.

In our series $19.47 \%$ of our patients had benefited from MRI, it showed precisely the mapping of the lesions. On the other hand, in the Obilat series, $2 \mathrm{O}$ patients (44.4\%) had benefited from this examination and in Elboukili $84 \%$ of the cases.

These results do not correspond to our results, this has explained by our socio-economic realities in our regions in Senegal, and The MRI is not available to all our patients for reasons of poverty and lack financial resources.

However, any suspicion of spinal cord compression should benefit from an emergency MRI. The spine scanner can be used quickly, with excellent performance in the spinal canal [15] [16].

However, the contribution of scan in the diagnosis of intracanal expansive processes had reduced.

The marrow is rarely found on axial cuts, except for the cervical upper region or the arachnoid spaces are broad [3] [12] [17] [18] [19]. 17 patients (15.04\%) had the spine scan.

Myeloscanner is the technique of choice for exploring and obtaining a fine tomographic analysis of the lesions inside the spinal canal: the size, the shape of the medullary cord and the spaces under arachnoid. The medullary parenchyma remains difficult to assess [20]. It was be performed in 04 patients (3.54\%). Since the advent of MRI, myelography has lost his predominant place in the exploration of the marrow and its envelopes. Currently, the only indications for the use of myelography are the contraindications of MRI [20].

2 patients (1.77\%) had benefited from standard myelography before 2008 .

The face and profile shots, accompanied by shots of three quarters allowed us to study the entire segment considered. If necessary, localized plaques may be made, either in an area that is difficult to analyze, such as the cervico-occipital hinge, or in a clinically suspected area [15] [21].

In our series, 63 patients (55.75\%) benefited from the standard radiography. Spinal injuries were found in most dorsal cases (46\%) followed by lumbar involvement (27\%). This is consistent with the results of numerous publications (Table 5).

\section{Etiologic and Evolutionary Data}

In the Diallo.S study, tuberculosis remains the first etiology of the child's spinal cord compression with $67.50 \%$ of cases and the tumors come second with $15 \%$ [1].

In our study, infectious causes were predominant (83\%) with a high frequency of Pott's disease $(80 \%)$, followed by tumor etiology (17\%). These results are 
Table 5. Global seat.

\begin{tabular}{ccccc}
\hline Seat & $\begin{array}{c}\text { Obilat [8] } \\
\%\end{array}$ & Our Study \% & $\begin{array}{c}\text { Elboukili [3] } \\
\%\end{array}$ & $\begin{array}{c}\text { Arthuis [9] } \\
\%\end{array}$ \\
\hline Cervical & & 4 & 08 & \\
Dorsal & 37.7 & 46 & 64 & 53.33 \\
Lumbar & & 27 & 12 & \\
Mixte & 24.4 & 23 & 32 & 23 \\
\hline
\end{tabular}

consistent with the data from Diallo.S 10, however, compared with other studies in Morocco and America, a predominance of tumor etiology was found [22].

\subsection{Pott's Disease}

The frequency of Pott's disease in Senegal in pediatric patients has estimated at $2.37 \%$ [23].

Children aged 0 to 15 years account for $24 \%$ to $55.09 \%$ [24] [25].

Pott's disease remains the first etiology encountered in our study, $80 \%$ of children suffering from Pott's disease responsible for spinal cord compression.

The mean age was 7.3 years with extremes of 1 year 3 months and 17 years, Mabiala et al. [26] had returned to an average age of 7.5 years with extremes of 11 months and 17 years.

We also report a male predominance with $60 \%$ of cases. These data is are be found it in other works [2] [4] [5].

The concept of counting was be found in 23 patients (25.55\%) of the cases, in the Ndiaye series $25.92 \%$ and in that of Mabiala et al. 50\% [26].

We have 52 Patients (57.78\%) had received BCG vaccination (Bacille de Calmette and Guérin), 12 patients (13.33\%) had not been vaccinated in the study of Mabiala et al. 36 patients (39.13\%) had not been vaccinated with BCG [26].

The concomitant involvement of the pleuropulmonary system was be found in $47.78 \%$ of our cases. Our results are relatively comparable to the results of Ndiaye, Eric, Loembe, Mabiala et al. Which gave 29.62\%, 31\%, 25.32\% and $44.56 \%$, respectively.

Apart from pleuropulmonary involvement, we obtained $15.55 \%$ lymph node location and $7.78 \%$ neuro-meningeal localization, which illustrates perfectly the data of the literature: all the viscera and noble organs of the organism can be affected [25] [26] [27] [28].

The HIV had not be found about all patients who be tested, we think that because they are young people and their parents was not HIV and the child had not any contexte to contract this.

The intradermal-tuberculin reaction was positive in 64 patients $(84.37 \%)$ of the cases that has be clinically tested. This result agrees perfectly with the results of Ndiaye [4] which found $83.33 \%$ and other data from the literature which vary between $62 \%$ to $91.61 \%$ of cases [24] [25] [26] [29]. 
In our series, $66.67 \%$ of our patients had paralysis of the lower limbs. HOFFMAN found $39.06 \%$ in a series of children with Pott's disease [29].

Eric found $66 \%$ in a general population [27], Mabiala et al. Accounted for $37 \%$.

However, Ndiaye had 100\% lower limb paralysis in his series. Our results are perfectly because our series of studies was multicentric (Pediatrics, Neurology, Neurosurgery) whereas the Ndiaye series has only used for neurology and most of the children in his series came to consult Paralysis of the lower limbs.

The second major sign in our series was a spinal deformity of 53.33\% kyphosis, $26.67 \%$ gibbosity, $23.33 \%$ scoliosis. Ndiaye [4] found a gibbosity in $55.55 \%$ in his series we find rather 53.33\% kyphosis, however Eric and Loembe [25] [27] had regained a gibbosity in $38.31 \%$ to $52 \%$, our results approach significantly.

The rate of sedimentation was high and CRP (chain reaction protein) was highly positive in $75.55 \%$ of the cases. These results are comparable to other studies [4] [26] [27].

The koch bacillus was searched in 62 patients $(68.89 \%)$ and was found in $6.45 \%$ of the cases, Loembe found in $28.12 \%$ of its patients [25].

The anatomy of cytology and pathology revealed a multinucleated giant cell histiocytic granuloma with tuberculoid or tuberculous tuberculous necrosis in the patient of our series.

Dorsal location was the most frequent in our study series $(46.67 \%)$, followed by lumbar localization $(26.67 \%)$, which is comparable to the data in the literature (Table 6).

The number of vertebrae reached at the imaging performed in 79 patients was two in the majority of cases $49.36 \%$ as reported in other series, $65.38 \%$ in the Ndiaye series, 44\% Hoffman and 36\% in the Garst series [4] [28] [29]. (Figure 1)

All authors agree on the principle of antituberculous chemotherapy for 9 to 12 months of treatment for patients with Pott's disease. This treatment is associated with a corset, this association is indicated in the child with a minimal deformation and a neurological deficiency less severe [24] [25] [30] [31] [32].

Table 6. Comparative table of vertebral sites during Pott's disease.

\begin{tabular}{|c|c|c|c|c|c|c|}
\hline Seat & $\begin{array}{c}\text { our } \\
\text { study } \\
\%\end{array}$ & $\begin{array}{c}\text { Ndiaye } \\
{[4]} \\
\%\end{array}$ & $\begin{array}{c}\text { Hoffman } \\
{[29]} \\
\%\end{array}$ & $\begin{array}{c}\text { Myung } \\
{[31]} \\
\%\end{array}$ & $\begin{array}{c}\text { Loembe } \\
\text { [25] } \\
\%\end{array}$ & $\begin{array}{c}\text { Mabiala } \\
{[26]} \\
\%\end{array}$ \\
\hline Cervical & 3.33 & 7.69 & & 11.11 & & 6.5 \\
\hline Cervico-Dorsal & 3.33 & 3.84 & 3 & & & 1.1 \\
\hline Dorsal & 47.78 & 73.07 & 55 & 88.88 & 36.40 & 43.5 \\
\hline \multicolumn{7}{|l|}{ Dorso- } \\
\hline lumbar & 15.55 & 7.69 & 10 & & 10.30 & 17.4 \\
\hline Lumbar & 26.67 & 7.69 & 28 & & 33.60 & 23.9 \\
\hline
\end{tabular}



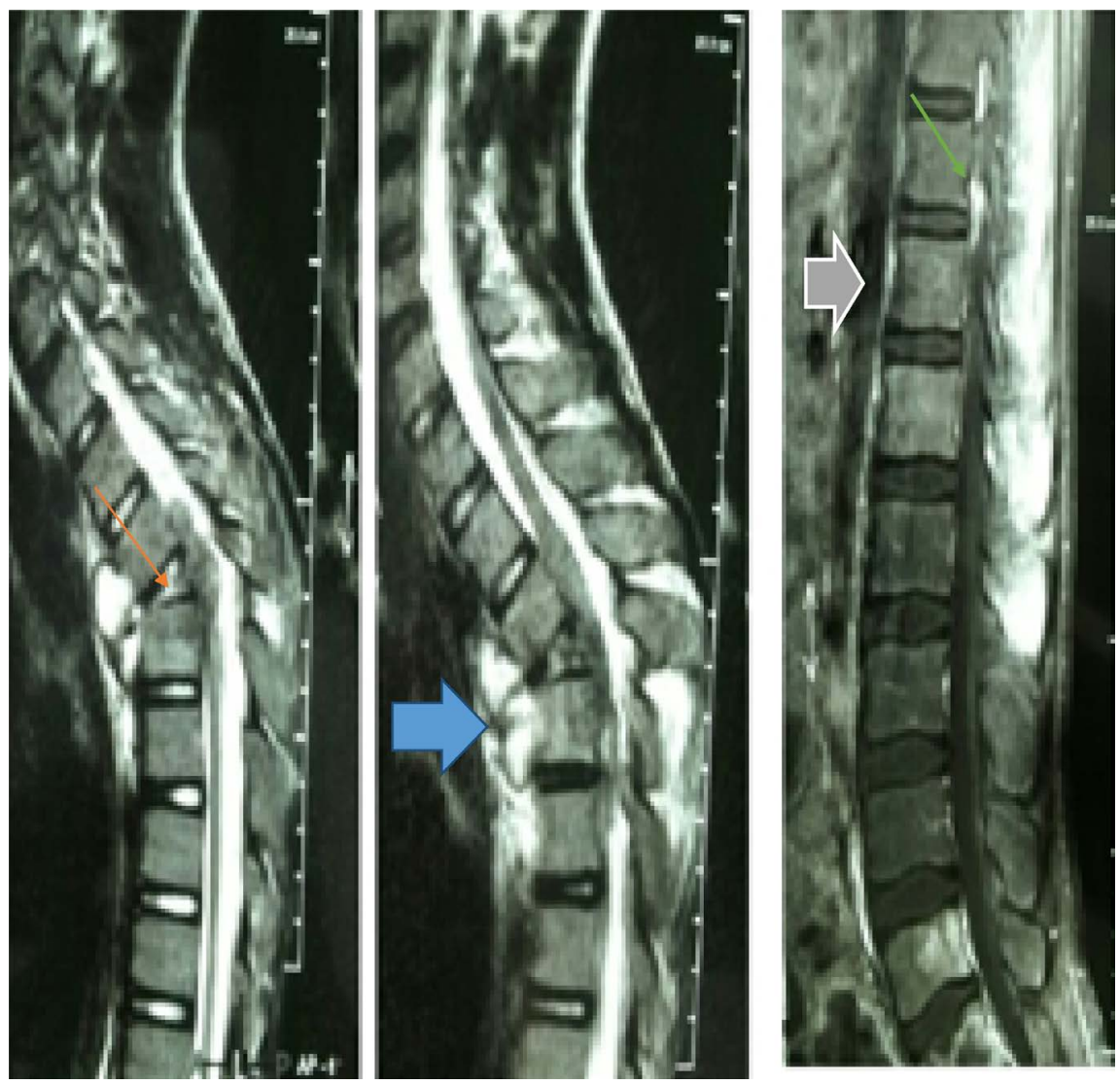

Figure 1. T2 Spinal Cord MRI, D4-D5 tuberculosis disco-vertebrae infection with Kyphotic angulation and pre-vertebral and epidural abscess.

In our series, Pott's disease has occurred on the AS sickle cell (10\%), we have $13 \%$ of malnutrition, 03 cases of type 1 diabetes, 01 case of acute lymphoid leukemia type 1, trisomy 21 (01 case), congenital heart disease (02 cases).

All our patients benefited from antituberculous chemotherapy associated with a corset in $88.89 \%$ of cases. 02 patients had benefited from decompressive laminectomy and ostéosynthésis in neurosurgery with anti-tuberculosis treatment.

\subsection{Spondylodiscitis with Banal Germs}

In children, we observe rather spondylodiscitis, The attack can sometimes be brutal thus achieving a picture of vertebral osteomyelitis [33].

We report three (03) cases of spinal cord compression in our series.

We have two girls for one boy. The extreme ages were 5 years and 12 years 6 months, the average age was 8.5 years. The affected levels were lumbar in all cases. All our patients had a standard X-ray. The spinal sites were disc and vertebral lumbar in the 3 patients. The isolated germs were, Aureus Meti Staphylococcus, Gram Negative Anaerobic Bacillus, Streptococcus A.

In the Zomaleto series the predominant disco-vertebral lesions were lumbar associated with neurological suffering and the predominant isolated bacteria were gram negative bacilli [34]. 


\subsection{Spinal Cord Compression by Bilharzia}

The treatment of this localization is above all medical, the excision of the intramedullary granulomas is discouraged by the majority of the authors [3].

In our patient the diagnosis was selected after laminectomy T12 to L2, myelotomy and total excision of intramedullary macroscopic lesion simulating an intramedullary tumor foranatomy pathological cytology which had demonstrated a granulomatous rearrangement withmicroabscess associated with parasitic structures suggestive of bilharziasis. (Figure 2, Figure 3)

The authors report that this is a rare cause of bone marrow compressions BA.MC et al. [35].

\subsection{Tumors Etiology}

They represent $17 \%$ of the causes of spinal cord compression in our series. This is consistent with Diallo's findings, which found tumor causes in $15 \%$ of cases [1].

We report $36.84 \%$ intramedullary lesional process, $42.11 \%$ intradural and extramedullary process and $21.05 \%$ extradural process. These lesions were extended in height in 09 patients, in width in 3 patients, in comparison with the posterior vertebral arches in 05 patients, and in 02 patients in the lower ones.

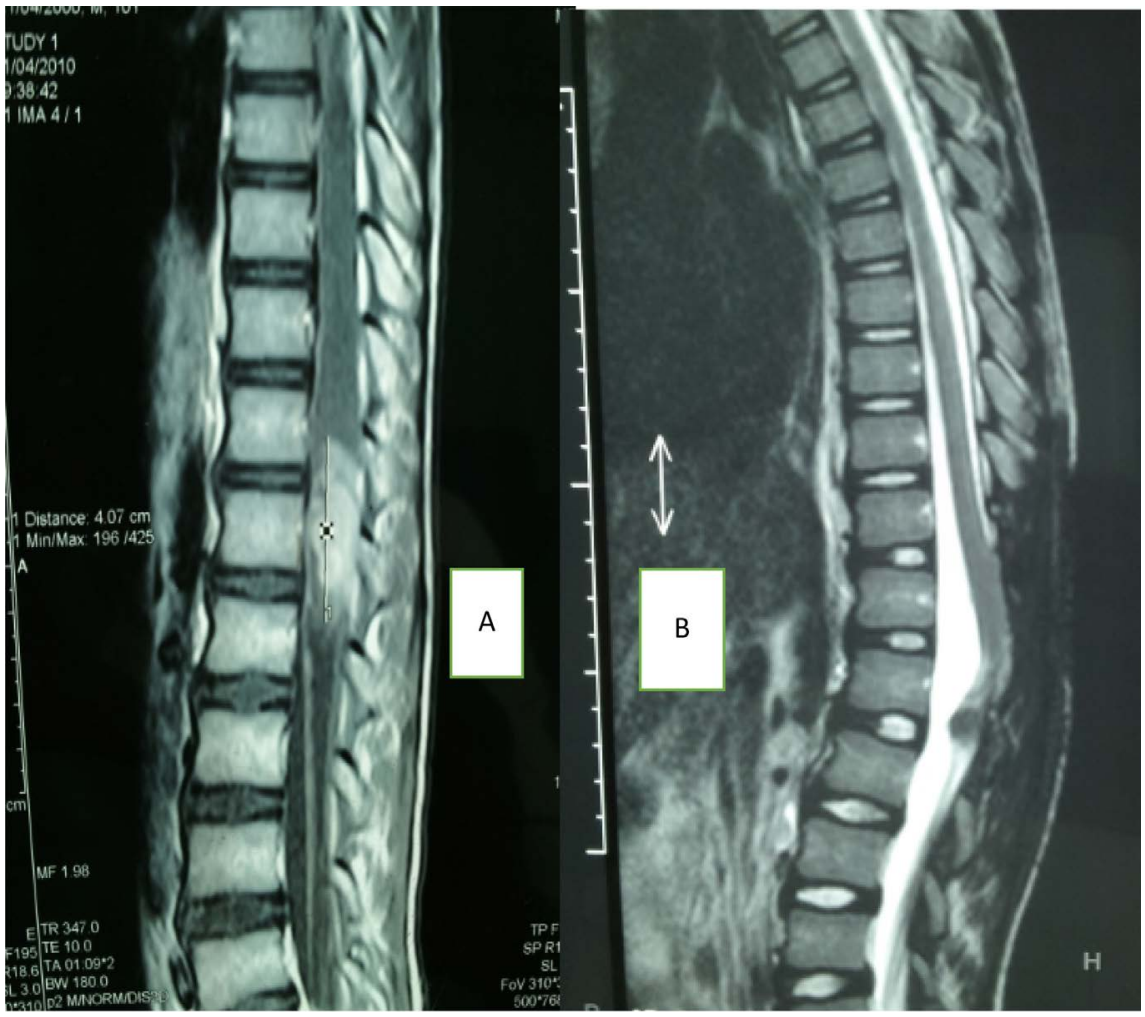

Figure 2. (A) MRI, intramedullary process at L1 measuring $4 \mathrm{~cm}$ in height and $1.5 \mathrm{~cm}$ in transverse diameter. (B) MRI of control, marked regression of the lesions of the terminal cone, with marked decrease of the medullar caliber and an expansion in the anterior arachnoid space. Bilharzia. 


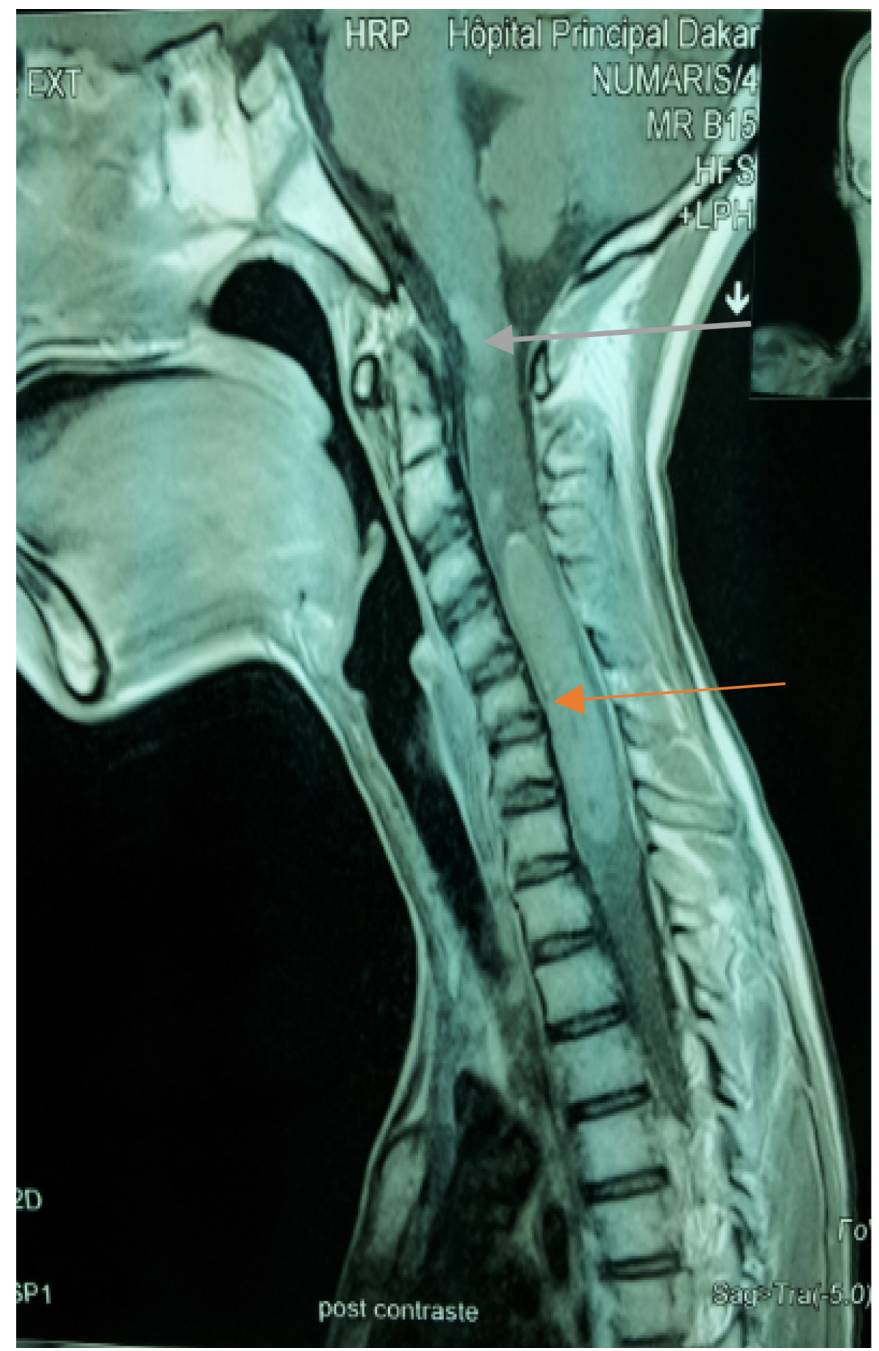

Figure 3. Cervical MRI, intradural process in hyper signal T2 of 9 $\mathrm{mm}$ pushing the bulbar marrow to the left, voluminous expanded cervical intramedullary process extended from C3 to C7. Intramedullary arachnoid cyst.

Our results are somewhat closer to the results of Obilat [8] who had $33.3 \%$ of extramedullary intradural tumors in his study series, Elboukili [3] who had 28\% intramedullary tumors in his series.

EL Mahdi et al. [36] found 33.33\% for each topographic type of process, and Lefebvre et al. [37] who had recovered $61.11 \%$ extradural tumor process.

The majority of the dorsal floor was in our series, ie $47.37 \%$. EL Mahdi et al. [36] found it in $58.77 \%$ of the cases in their series.

The histology in 6 patients showed 5.26\% type II neurofibroma (Figure 4), $5.26 \%$ extramedullary intradural arachnoid cyst, 5.26\% intramedullary arachnoid cyst with cytochemistry of the CSF - like content, 5.26\% 5.46\% grade I terminal cone ganglioneurinoma and 5.26\% meningothelial meningioma. Our results are comparable to data from the literature [3] [36] [38].

Elboukili [3] found $8 \%$ arachnoid cyst in his series, $12 \%$ ependymoma. Saouab 


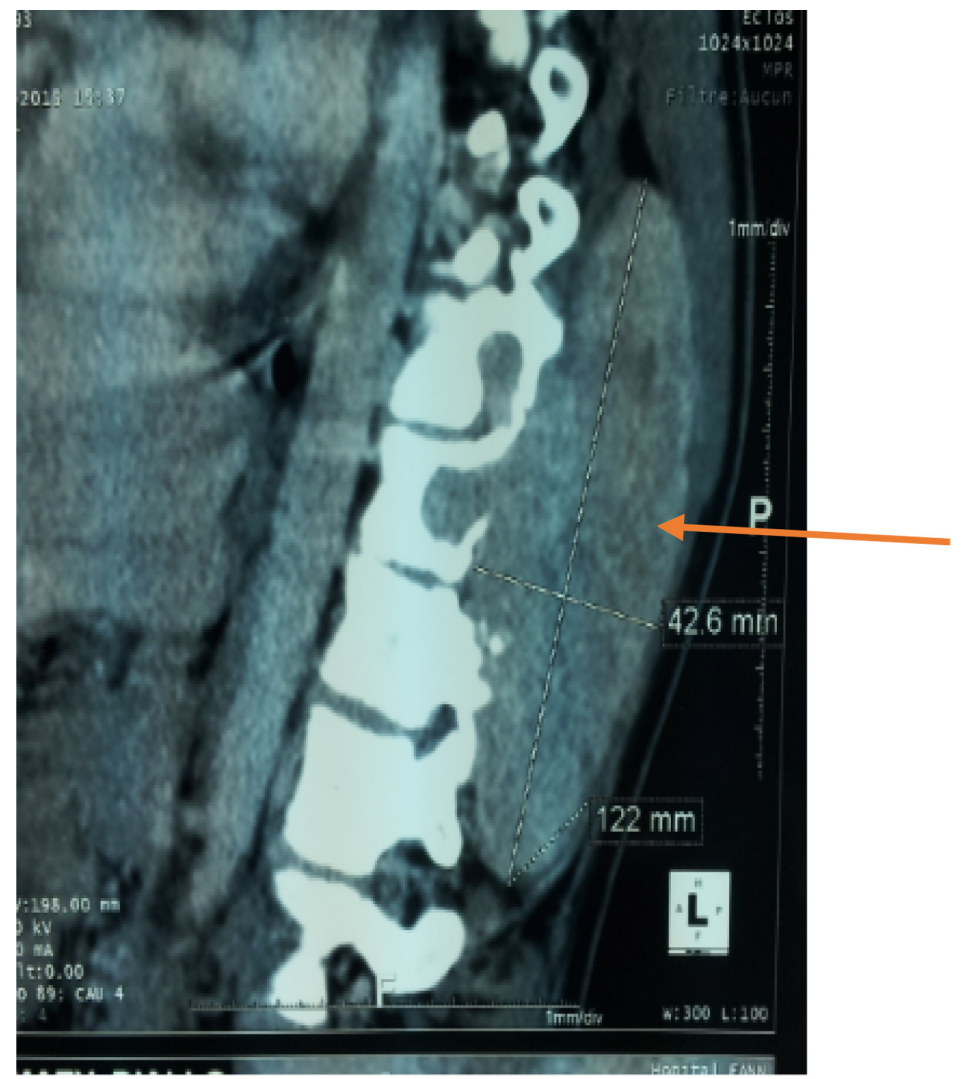

Figure 4. CT scan "hourglass appearance" neurofibroma Type II extra and intra canal Dorsal expanding foramen D9 and D10.

[39] reported a case of ganglioneurinoma in his series with $3.64 \%$ astrocytomas, EL Mahdi [36] found $4.83 \%$ of meningiomas.

$94.74 \%$ of our patients had benefited from decompressive laminectomy with tumor excision.

Some authors prefer a laminotomy to laminectomy in all cases where it is possible to minimize the risk of destabilization of the spine after the opening of the spinal canal [38].

\section{Conclusions}

Non-traumatic spinal cord compression is a serious condition and is a diagnostic and therapeutic emergency especially in the growing child.

In Africa, particularly in the tropics, Pott's disease remains the first etiology followed by vertebro-medullary tumors. They are also due rarely to disco-vertebral lesions with mere germs and intramedullary parasitoses such as bilharziosis. Imaging is of paramount importance, especially magnetic resonance imaging, which remains the exam of choice for a precise neuroradiological diagnosis of medullary pathology. Depending on the etiology, the treatment is medical and/or neurosurgical. The progression under treatment is often favorable with some sequelae; some patients recover totally from their neurological deficit, other patients can develop complications and die. 


\section{References}

[1] Diallo, S. (1991) Le Mal de Pott à Dakar; étude rétrospective hospitalière à propos de 617 dossiers colligés de janvier 1980 à décembre 1990. Thèse Med Dakar No. 49.

[2] Basu, S.N. and Dutta, D. (1997) No Traumatic Paraplégia of Upper Motor Neurone Origin Children. A Review of Fifty-Eight Cases. The Indian Journal of Pediatrics, 44, 2156-2219.

[3] Elboukili (2012) Prise en charge des compressions médullaires non traumatiques chez l'enfant, étude retrospective de janvier 2002 au 31 décembre 2010 à propos de 25 cas. Thèse No. 19 Medecine Marrakech 2012.

[4] Ndiaye, M., Sene-Diouf, F., Diop, A.G., Sakho, Y., Ndiaye, M.M. and Ndiaye, I.P. (1999) Compression médullaire pottique de l'enfant. Dakar Medical, 44, 49-53.

[5] Silva, F. (1973) Some Experiences with Non-Traumatic Paraplegia in Malaysia. Paraplegia, 2, 146-158. https://doi.org/10.1038/sc.1973.19

[6] Chamberlain, M.C. and Kormanik, P.A. (1999) Epidural Spinal Cord Compression: A Single Institution's Retrospective Experience. Neuro-Oncology, 1, 120-123. https://doi.org/10.1093/neuonc/1.2.120

[7] Epstein, F.J. and Ragheb, J. (1994) Intramedullary Tumors of the Spinal Cord. Pediatric Neurosurgery. 3rd Edition, W.B. Saunders, Vol. 36, 446-57.

[8] Obilat, H. (2003) Les compressions médullaires non traumatiques de l'enfant. Thèse Doctorat Medecine Casablanca, No. 150, 164 p.

[9] Arthuis, M. and Turpin, J.C. (1973) Etude Clinique des compressions de la moelle et de la queue de cheval chez l'enfant. CMNT de l'enfant, MASSON et CIE, Edition, $1-18$.

[10] Bernardi, B., Pionca, C. and Pistamiglo, P. (2001) Neuroblastome with Symptomatic Spinal Cord Compression. Journal of Clinical Oncology, 19, 183-190.

https://doi.org/10.1200/JCO.2001.19.1.183

[11] Lewis, D.W., Packer, R.J., Raney, B., Rak, I.W., Belasco, J. and Lange, B. (1986) Incidence, Presentation and Outcome of Spinal Cord Disease in Children with Systemic Cancer. Pediatric, 78, 438-443.

[12] Braun, M., Anxionnat, R., Moret, C., Bracard, S., Picard, L. and Marchal, C. (2003) Imagerie médullorachidienne. Editions scientifiques et médicales Elsevier SAS. Neurologie, 17-035-A-60.

[13] Lyon, G. and Evrard, P. (1987) Tumeurs intrarachidiennes chez l'enfant. Neuropédiatrie, Edition Masson, 23, 95-99.

[14] Manelfe, C. (1989) Imagerie du rachis et de la moelle. Scanner, IRM et Ultra-sons. 1 Vol. Vigot Paris

[15] Chelli Bouaziz, M., Ladeb, M.F. and Chakroun, M. (2009) Chaabane, S. Imagerie de la tuberculose rachidienne. Encyclopédie médico-chirurgicale, Neuroradiologie, 31-670-C-10.

[16] Floubes-Lacroix, F., Gozlan, A., Cognard, C. and Manelfe, C. (2004) Imagerie diagnostique de la spondylodiscite infectieuse. Encyclopédie médico-chirurgicale. Radiologie et imagerie médicales, 31-335-A-10.

[17] Benchad, M. (2009) Prise en charge des tumeurs intramédullaires. These Doctorat Medecine, Marrakech, No. 21, 142 p.

[18] Holl, N., Kremer, S., Wolfram-Gabel, R. and Dietemann, J.L. (2010) The Spinal Canal: From Imaginig Anatomy to Diagnosis. Journal of Radiology, 91, 950-968. https://doi.org/10.1016/S0221-0363(10)70142-6 
[19] Sun Hahn, Y. and McLone, D.G. (1984) Pain in Children with Spinal Cord Tumors. Child s Brain, 11, 36-46. https://doi.org/10.1159/000120158

[20] Nima, H. (2006) Anatomie et radio anatomie de la moelle 2006. Thèse Doctorat Medecine Casablanca, No. 297, 118 p.

[21] Schiff, D. (2003) Spinal Cord Compression. Neurologic Clinics of North America, 21, 67-86. https://doi.org/10.1016/S0733-8619(02)00033-6

[22] Dincer, F., Celiker, R., Ozker, S., Basgoze, O. and Ozker, R. (1993) Etiological and Functional Evaluation of Pediatric Population with Spinal Cord Injuries Turk. Journal of Pediatrics, 35, 173-175.

[23] Khoo, L., Mikawa, K. and Fessler, R. (2003) A Surgical Revisitation of Pott Distemper of the Spine. The Spine Journal, 3, 130-145. https://doi.org/10.1016/S1529-9430(02)00410-2

[24] Alliez, B., Sena, J.C. and Ducolombier, A. (1995) Paraplégie Pottique: 65 Observations: Indications therapeutiques en milieu africain. Medecine d Afrique Noire, 4, 410-441.

[25] Loembe, P.M., Assengone Zey, Y., Guerch, M. and Mbumb King, A. (1988) La tuberculose vertébral au Gabon, Aspects anatomo-cliniques, problèmes diagnostiques et thérapeutiques 107 cas de 1976 à 1986. Neurochirurgie, 34, 420-427.

[26] Mabiala Babela, J.R., Makosso, E., Nzingoula, S.P. and Senga, P. (2005) Aspects radiologiques du mal de Pott chez l'enfant. À propos de 92 cas. Bulletin De La Societe De Pathologie Exotique, 98, 14-17.

[27] Eric, S.N., Gaylan, L.R. and Thomas, A.B. (1995) Spinal Tuberculosis: A Diagnostic and Management Challenge. Journal of Neurosurgery, 83, 243-247.

[28] Garst, R.J. (1992) Tuberculosis of the Spine: A Review of 235 Operated Cases in an under Developed Region from 1954 to 1964 (See Comments). Journal of Spinal Disorders, 5, 286-300. https://doi.org/10.1097/00002517-199209000-00006

[29] Hoffman, E.B., Crosier, J.H. and Cremin, B.J. (1993) Imaging in Children with Spinal Tuberculosis, A Comparaison of Radiography Computed Tomography and Magnetic Resonance Imaging. The Journal of Bone and Joint Surgery, 75, 233-239.

[30] Galvagno, G. and Meo, G. (1991) Treatment of Pott's Paraplegia in a Rural African Hospital. East African Medical Journal, 68, 124-129.

[31] Myung-Sang, M., Kee-Young, H., Doo-Hoon, S. and Jeong-Lim (1996) Pott's Paraplégia. Clinical Orthopaedics and Related Research, 323, 122-128.

https://doi.org/10.1097/00003086-199602000-00017

[32] Sayi, E.N. and May, S.M. (1995) Tuberculosis of the Spine in Children at Muhimbill Medical Center-Dar Es Salam. East African Medical Journal, 72, 46-48.

[33] Dubost, J.J., Tournadre, A., Soubrier, M. and Ristori, J.M. (2010) Spondylodiscite Infectieuse Non Tuberculeuse. Encyclopedie Medico-Chirurgicale, 15-860-A-10.

[34] Zomaleto, Z., Kobelembi, A., Agbodande, A., Dossou-yovo, H., Zossoungbo, F. and Avimadje, M. (2015) Profil épidémio-clinique, paraclinique et thérapeutique des spondylodiscites à germes banals en consultation hospitalière à Cotonou(Bénin). Médecine d' Afrique Noire, 62, 405-409.

[35] Ba, M.C., Thiam, A.B., Ndoye, N., Wahab, I., Thioub, M., Sakho, Y. and Badiane, S.B. (2012) A Rare Etiology of Spinal Cord Compression. Neurochirurgie, 58, 272-274. https://doi.org/10.1016/j.neuchi.2012.04.003

[36] EL Madhi, T., Zentar, A., EL Azzouzi, M. and EL Khamlichi, A. (1996) Profil épidémiologique descriptif des tumeurs du système nerveux central à propos de 903 
cas (1983-1992). Médecine du Maghreb No. 59.

[37] Lefebvre, J., Klein, M.R., Lepintre, J. and Faure, C. (2010) Etude radiologique des tumeurs médullaires chez l'enfant. Acta Radiologica, 46, 48-54.

[38] Scavarda, D., Pech Gourg, G., Lena, G. and Chabrol, B. (2008) Tumeurs intrarachidiennes de l'enfant et du nourrisson. Elsevier Masson SAS, 4-100-E-10.

[39] Saouab, R. and Dafiri, R. (2009) Imagerie des rachialgies chez l'enfant (à propos de 110 cas). Journal de Radiologie, 90, 15-97.

https://doi.org/10.1016/S0221-0363(09)76278-X 